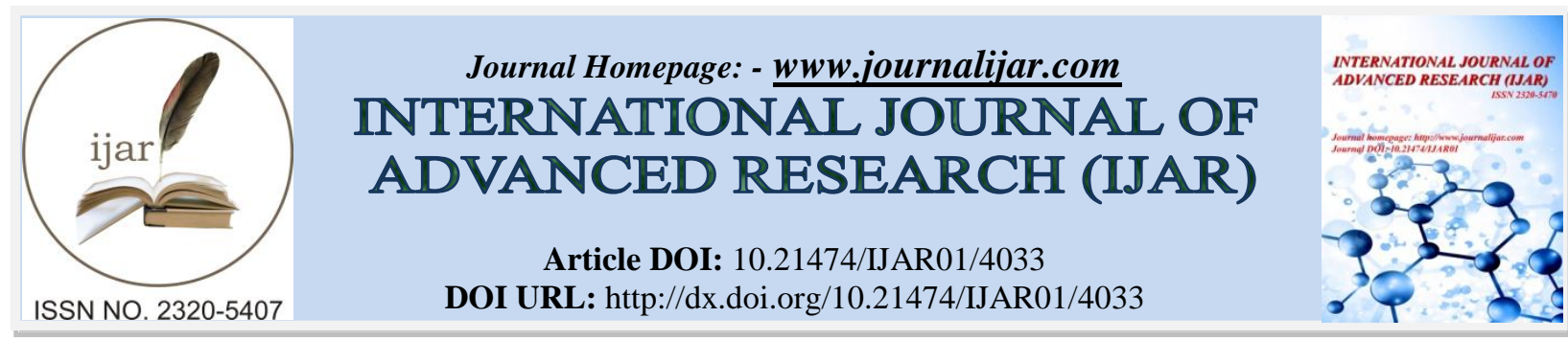

RESEARCH ARTICLE

\title{
SPECTROSCOPIC DETERMINATION OF HYDROCHLOROTHAIZIDE BY USING HYDROTROPIC SOLUBILISING AGENT.
}

\author{
Ms. Chetana D.Patil ${ }^{1 *}$, Mr Balaji W.Matore ${ }^{2}$ and Ms.Pallavi S.Dhekale ${ }^{1}, M$ Digamber N.Bhosale ${ }^{2}$ \\ 1. Assistant Professor,Department of Pharmaceutical Chemistry, GIPER, Limb,Satara: 415015, India. \\ 2. Department of Chemistry GIPER, Limb, Satara: 415015, India
}

\section{Manuscript Info}

Manuscript History

Received: 19 February 2017

Final Accepted: 21 March 2017

Published: April 2017

Key words:-

Hydrochlorothaizide, Hydrotropic

Solubilizing Agents and Validation.

\begin{abstract}
Analysis of drug utilized the organic solvent which are costlier, toxic, and causing environment pollution. Hydrotropic solution may be a proper choice to preclude the use of organic solvents so that an attempt has been made to develop simple, accurate, novel, safe and precise spectrophotometric method for estimation of poorly-water soluble drug Hydrochlorothaizide. Solubility of Hydrochlorothaizide is increased by using tri-sodium citrate and urea solution as hydrotropic agent. There was more than 28 fold solubility enhanced in hydrotropic solution as compare with distilled water. The Hydrochlorothaizide shows the maximum absorbance at $271 \mathrm{~nm}$. At this wavelength hydrotropic agent and other tablet excipients do not shows any significant interference in the spectrophotometric assay. The developed method was found to be linear in the range of $5-25 \mu \mathrm{g} / \mathrm{ml}$ with correlation coefficient (r2) of 0.999. The mean percent label claims of tablets of Hydrochlorothaizide in marketed formulation estimated by the proposed method were found to be $99.91 \pm 0.04$ respectively. The developed methods were validated according to ICH guidelines and values of accuracy, precision and other statistical analysis were found to be in good accordance with the prescribed values. As hydrotropic agent used in the proposed method so this method is eco-friendly and it can be used in routine quantitative analysis of drug in bulk drug and dosage form in industries
\end{abstract}

Copy Right, IJAR, 2017,. All rights reserved.

\section{Introduction:-}

Hydrochlorothaizide is an thiazide analog acts as diuretic and antihypertensive drug. reduces blood volume by acting on the kidneys to reduce $\mathrm{Na}^{+}$reabsorption in the DCT. The molecular formula is $\underline{\mathrm{C}}_{7} \underline{\mathrm{H}_{8}} \underline{\mathrm{ClN}}_{\underline{3}} \underline{\mathrm{O}}_{4} \underline{\mathrm{S}}_{2}$. The chemical name is 6-chloro-1,1-dioxo-3,4-dihydro- $2 \mathrm{H}$-1,2,4-benzothiadiazine-7-sulfonamide . It is slightly soluble in water, whereas freely soluble in ethanol, methanol and dilute acids and alkali. ${ }^{[1,10]}$

Increasing the aqueous solubility of insoluble and slightly soluble drugs is of major importance. Various techniques have been employed to enhance the aqueous solubility of poorly water-soluble drugs. ${ }^{[3,4]}$ Hydrotropic solubilization is one of them. The term hydrotropy has been used to designate the increase in solubility of various substances in water due to the presence of large amounts of additives. Drawbacks of organic solvents include higher cost, toxicity, pollution, and error, in analysis due to volatility. Hydrotropic solubilization process involves cooperative intermolecular interaction with several balancing molecular forces, rather than either a specific complexation event

Corresponding Author:- Ms. Chetana D.Patil.

Address:- Assistant Professor,Department of Pharmaceutical Chemistry, GIPER, Limb,Satara: 415015, India. 
or a process dominated by a medium effect, such as co-solvency or salting-in. hydrotropic agents have been observed to enhance the aqueous solubility of poorly water soluble drugs. ${ }^{[5,6,7]}$ Hydrotropy can be considered to be a potentially and industrially attractive technique since the observed increase in solubility is much higher than that affected by other solubilization methods. Solvents such as tri-sodium citrate, and urea have been employed to enhance the aqueous solubility of poorly water-soluble drugs. ${ }^{[1,2,5,6,10]}$ Various organic solvents like methanol, chloroform, alcohol, dimethyl formamide, and benzene have been employed for the solubilization of poor water soluble drugs for their analysis.

Fig. 1:- Chemical structure of Hydrochlorothaizide

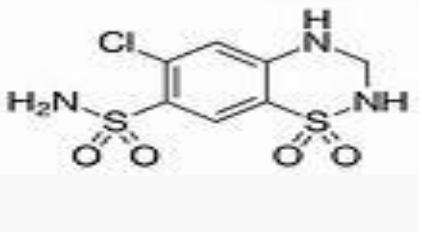

\section{Materials and Methods:-}

Hydrochlorothaizide bulk drug was a gift sample from Remidex Pharmaceuticals, Bangalore. Urea and tri-sodium acetate was purchased from Rankem, New Delhi. Tablets of Hydrochlorothaizide were purchased from local market. Shimadzu UV/Visible recording spectrophotometer (model-UV-1601) with $1 \mathrm{~cm}$ matched silica cells was employed. All other chemicals and solvents used were of analytical grade.

\section{Preliminary Solubility Studies:-}

Solubility of HCT was determined at $28 \pm 1^{\circ} \mathrm{c}$. An excess amount ofdrug was added to screw capped $30 \mathrm{ml}$ glass vials containing different aqueous systems viz.distilled water, $1 \mathrm{M}$ urea and $1 \mathrm{M}$ trisodium citrate solution. There was more than 30 and 48 fold solubility enhanced in sodium acetate as compare with distilledwater. This enhancement of solubility is due to the hydrotropic solubilization phenomenon.

\section{Preparation of calibration Curve:-}

Accurately weighed 100mg of HCTZ drug sample were transferred in to $100 \mathrm{ml}$ volumetric flask containing $10 \mathrm{ml}$ of $1 \mathrm{M}$ trisodium citrate solution and $1 \mathrm{M}$ urea diluted up to $100 \mathrm{ml}$ with distilled water. The standard solution 1000 $\mu \mathrm{g} / \mathrm{ml}$ was further diluted with distilled water to obatain 5,10,15,20,25 $\mu \mathrm{g} / \mathrm{ml}$. detection wavelength was selected for HCT was $271 \mathrm{~nm}$. Absorbance was noted against distilled water asbetween concentration verses wavelength

\section{Analysis of tablet Formulation:-}

Twenty tablets of Hydrochlorothaizide (Hydrazide25) were weighed and finely powdered. Powder equivalent to 50 $\mathrm{mg}$ of hydrochlorothiazide was taken in a $100 \mathrm{ml}$ volumetric flask $10 \mathrm{ml}$ of mixed hydrotropic solution of $1 \mathrm{M}$ trisodium citrate and $1 \mathrm{M}$ urea was added and the flask was shaken properly for $10 \mathrm{~min}$. to solubilize the drug and the volume was made up to the mark with distilled water. After filtration through a Whatmann filter paper no. 41, the filtrate was appropriately diluted with distilled water for spectrophotometric estimation against reagent blank to calculate the drug content.

\section{Validation Method:- \\ Linearity:-}

Appropriate concentration of stock solution was assayed as per developed methods. Beer-Lambert's concentration range was found to be $5-25 \mu \mathrm{g} / \mathrm{ml}$. The linearity data for both methods are presented in Table No.1.

\section{Accuracy:-}

To check the degree of accuracy of the method, recovery studies were performed in triplicate by standard addition method at $80 \%, 100 \%$ and $120 \%$. In pre-analyzed tablet solution, a definite amount of drug was added and then its recovery was studied. These studies were performed in by adding fixed amount of pure drug solution to the final dilution while varying the concentration of tablet sample solution in the final dilution 


\section{Precision:-}

Precision of the methods was studied at three level as at repeatability, intermediate precision (Day to Day and analyst to analyst) and reproducibility. Repeatability was performed by analyzing same 5 concentrations of drug for 5 times. Day to Day was performed by analyzing 5 different concentration of the drug for three days in a week. Reproducibility was performed by analyzing same concentration of drugs for five times in different lab.

\section{Statistical validation:-}

To check the degree of precision of the method, suitable statistical evaluation was carried out. Six samples of the each tablet formulation were analyzed as per the procedure given above. The standard deviation (S.D.), Percent Relative Standard Deviation (\%R.S.D.), Percent Recovery, Amount found, L.O.D., L.O.Q.,

\section{Results and Disscussion:-}

Linearity, range and calibration curve:-

Based on the solubility, stability and spectral characteristics of the drug, mixture of $1 \mathrm{M}$ tri-sodium citrate and $1 \mathrm{M}$ urea solution was selected as hydrotropic agent. There was more than 28 fold solubility enhanced in mixed hydrotropic solution as compare with distilled water. After Solubilizing the Hydrochlorothaizide in selected hydrotropic agent, it was scanned in spectrum mode and the working wavelength for the estimation, considering the reproducibility and variability was found to be $271 \mathrm{~nm}$. The developed method was found to be linear in the range of $5-25 \mu \mathrm{g} / \mathrm{ml}$ with linear equation was $\mathrm{Y}=0.0361 \mathrm{X}+0.163$ and correlation coefficient $(\mathrm{r} 2)$ of 0.999 . Calibration curve was plotted between concentrations versus absorbance Figure 3. Observation of linearity data has been reported in the Table 1. The Result of their optical characteristics has shown in Table 2.

Figure 2:- Spectra of MCM in Mixed Hydrotropic Agent

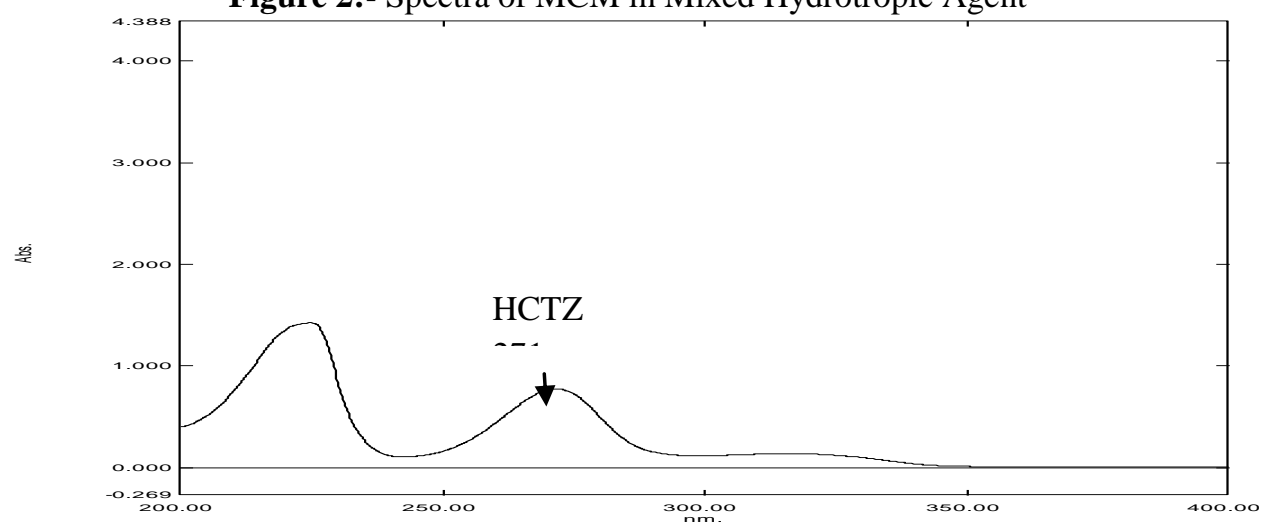

Fig no.3:- Calibration curve of pure Hydrochlorothaizide

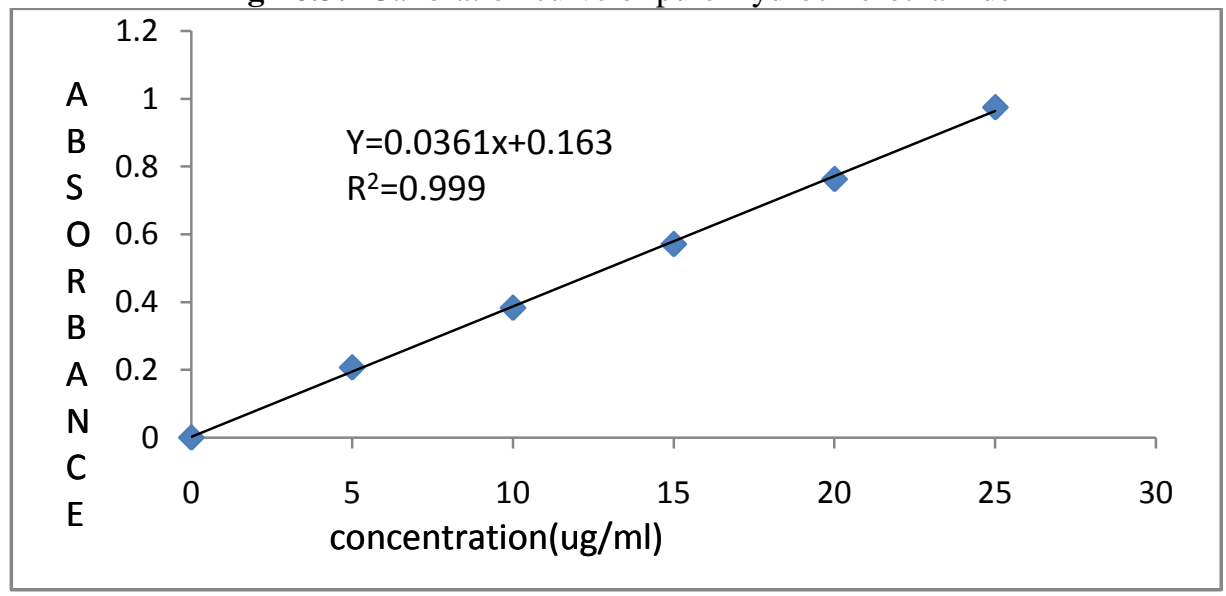


Table 1:- Optical Characteristic and Linearity Data of Hydrochlorothaizide in Mixed Hydrotropic Agent.

\begin{tabular}{|c|c|c|}
\hline Sr.No. & Parameter & Mixed hydrotropic agent \\
\hline 1 & Working $\lambda$ & $271 \mathrm{~nm}$ \\
\hline 2 & Beer's law limit $(\mu \mathrm{g} / \mathrm{ml})$ & $5-25$ \\
\hline 3 & Correlation coefficient $\left(\mathrm{r}^{2}\right)$ & 0.999 \\
\hline 4 & Slope $(\mathrm{m})$ & 0.0361 \\
\hline 5 & Intercept $(\mathrm{c})$ & 0.163 \\
\hline 6 & Number of sample $(\mathrm{n})$ & 5 \\
\hline 7 & L.O.D & 0.4795 \\
\hline 8 & L.O.Q & 1.598 \\
\hline
\end{tabular}

\section{Accuracy:-}

The mean percent label claims of tablets of HCTZ in formulation Hydrazide25 estimated by the proposed method were found to be $99.91 \pm 0.04$ respectively. These values are close to 100 , indicating the accuracy of the proposed analytical method. The statistical evaluation of tablet analysis is reported in Table 2 .

Table 2:- Results and Statistical Parameters for Hydrazide25 Tablet Analysis Using Mixed Hydrotropic Agent

\begin{tabular}{|c|c|c|c|c|}
\hline Drug & Label claim(mg) & Amount found & \% mean & SD( $( \pm)$ \\
\hline Hydrazide25 & 25 & 24.97 & 99.88 & 0.056 \\
\hline Hydrazide25 & 25 & 24.94 & 99.76 & 0.043 \\
\hline Hydrazide25 & 25 & 25.03 & 100.1 & 0.047 \\
\hline mean & & 24.98 & 99.91 & 0.044 \\
\hline
\end{tabular}

*Average of five in 3 replicates determination

\section{Percentage Recovery:-}

The percentage recovery and percentage relative standard deviation of the recovery were calculated and reported in Table 3.The values of mean percent recoveries were also found to show variability in ranging from $98.85 \pm 1.0$ to 99.98 \pm 0.02 . Low values of standard deviation, percent coefficient of variation and standard error further validated the proposed method.

Table 3:- Result of Recovery Studies of Tablet Formulation with Statically Evaluation.

\begin{tabular}{|c|c|c|c|c|}
\hline Drug & $\begin{array}{c}\text { Qc Concentration } \\
(\square \mathbf{g} / \mathbf{m l})\end{array}$ & $\begin{array}{c}\text { Recovery Level } \\
\text { \%(Amount Drug } \\
\text { Added) }\end{array}$ & $\begin{array}{l}\text { Amount Of Drug } \\
\text { Found } \\
(\text { Mean } \pm \text { Sd })\end{array}$ & $\%$ RSD \\
\hline \multirow{3}{*}{ Hydrazide25 } & \multirow{3}{*}{10} & 80 & $98.85 \pm 1.01$ & 0.31 \\
\hline & & 100 & $98.83 \pm 1.17$ & 0.12 \\
\hline & & 120 & $99.98 \pm 0.02$ & 0.01 \\
\hline \multirow[t]{3}{*}{ Hydrazide25 } & \multirow[t]{3}{*}{12} & 80 & $98.89 \pm 1.11$ & 0.045 \\
\hline & & 100 & $98.99 \pm 0.95$ & 0.021 \\
\hline & & 120 & $99.83 \pm 0.17$ & 0.063 \\
\hline
\end{tabular}

\section{Precision:-}

Result of precision at different level were found be within acceptable limits (RSD<2). The results have been reported in Table 4. Presence of hydrotropic agent do not shows any significant interference in the spectrophotometric assay thus further confirming the applicability and reproducibility of the developed method.

Table 4:- Result of Precision of Acivir-200.

\begin{tabular}{|l|c|c|c|}
\hline & Validation parameter & Percentage mean \pm SD & \% RSD \\
\hline \multirow{3}{*}{ Mixed hydrotropic agent } & Repeatability & $98.88 \pm 0.91$ & 0.11 \\
\cline { 2 - 4 } & $\begin{array}{c}\text { Intermediate Precision day } \\
\text { to day }\end{array}$ & $99.33 \pm 0.80$ & 0.13 \\
\cline { 2 - 4 } & Reproducibility & $99.56 \pm 0.44$ & 0.07 \\
\hline
\end{tabular}




\section{Conclusion:-}

It was thus concluded that hydrotropic solubilization is an effective technique in the enhancement of solubility of various poorly water soluble drugs. Hence the proposed method is new, simple, accurate, non-toxic and precise method. This method can be successfully employed for estimation of drugs in routine analysis of tablets.

\section{References:-}

1. Jain N, Jain R, Thakur N, Gupta B, Banweer J, Jain S. Novel spectrophotometric quantitative estimation of hydrochlorothiazide in bulk drug and their dosage forms by using hydrotropic agent. Int. J. Appl. Pharma. 2010; 2(3): 1114.

2. Gurumurthy Venkatesh et al,Spectrophotometric estimation of acyclovir using hydrotropic solubilsation phenomenon, Journal of Pharmacy Research , 2012,5(2),849-851.

3. K R Sreejith et al, A review on analytical methods based on hydrotropic phenomenon, European Journal Of Pharmaceutical And Medical Research, 2015,2(5), 1293-1319.

4. Ajit. K. Nangare et al, Development And Validation Of Uv Spectrophotometric Methods For Estimation Of Efavirenz In Bulk And Tablet Dosage Form, Asian Journal of Pharmaceutical Analysis and Medicinal Chemistry. 2(3), 2014, 134 - 144.

5. K. P. R. Chowdary et al, Recent Research On Formulation Development Of BCS Class II Drugs - A Review, International Research Journal of Pharmaceutical and Applied Sciences (IRJPAS),2013, 3(1): 173-181.

6. V.Gurumurthy et al, Application of mixed cosolvency concept in spectrophotometricestimation of acyclovir tablets, Pelagia Research Library ,Der ChemicaSinica, 2011, 2(6):198-203.

7. R. K. Maheshwari et al,Novel Spectrophotometric Estimation Of Some Poorly Water Soluble Drugs Using Hydrotropic Solubilizing Agents, Indian Journal Of Pharmaceutical Sciences, 2006, 195-198.

8. Siladityabehera et al,Uv-Visible Spectrophotometric Method Development And Validation Of Assay Of Paracetamol Tablet Formulation, J Anal Bioanal Techniques 2012, 3(6):1-6

9. Kapadiyanidhi et al, Hydrotropy: A Promising Tool For Solubility Enhancement: A Review 2011, 3(2): 26- 33

10. Ruchi Jain et al,Quantitative Estimation Of Meloxicam : A Novel Approach Using Hydrotropic Solubilization Technique, Asian J Pharm Clin Res,2013, 330-334 